Pecvnia, 10 (2010), pp. 203-229

\title{
Valoración de bienes rústicos de utilidad pública: La expropiación forzosa por las obras del AVE en la provincia de León
}

Recibido: Enero 2010

Aceptado: Marzo 2010

\author{
$M^{\mathrm{a}}$ del Pilar Gutiérrez Flórez \\ mpgutf@unileon.es \\ Universidad de León \\ E.S. y Técnica de Ingeniería Agraria \\ Avda. de Portugal, 41 \\ 24071 León (España)
}

Con motivo de la expropiación forzosa de fincas en la provincia de León debido a las obras del Tren de Alta Velocidad, AVE, los propietarios de ochenta y dos fincas de los Ayuntamientos de Villanueva de las Manzanas, Santas Martas y Vega de Infanzones, solicitaron un estudio de valoración alternativo de las mismas para presentarlo, en forma de alegaciones individuales, al Jurado Provincial de Expropiación Forzosa de León, tal y como es su derecho, según la Ley de Expropiación Forzosa, LEF, por su desacuerdo con la oferta de la Entidad Expropiante.

En este artículo se presenta el método, se justifican los criterios de valoración, se presentan y analizan los resultados obtenidos y se elaboran las conclusiones a partir de los
On the occasion of the necessary expropriation of lands in the province of León due to the works of the High-speed train, AVE (HIGH SPEED TRAIN), the owners of eighty two plots of Villanueva de las Manzanas, Santas Martas and Vega de Infanzones, requested an choice study of valuation of the same ones it to present, in the individual allegations, to the Provincial Juror of Necessary Expropriation of León, as it is your choice, according to the Spanish Law of Necessary Expropriation, LEF, for your disagreement with the offer of the Entity Expropriator.

In this article on presents the method, the criteria of valuation justify themselves, appear and analyze the obtained results and the conclusions are elaborated from the individual 
informes individuales, tras el reconocimiento de los terrenos afectados y su entorno, en base a datos obtenidos bien sea de la propia entidad expropiante bien de la normativa autonómica en vigor en el momento de la expropiación, o bien de la Ley del Suelo 8/2007 en lo referente a la toma de decisiones para el planteamiento de las hipótesis de partida del estudio.

Por último, se justifican la tasa del tipo de interés utilizado para la Capitalización de las rentas, en base a normativa vigente o estudios oficiales, y el coeficiente multiplicador del valor de las mismas, según los modelos territoriales de situación respecto a un núcleo urbano, ambos parámetros necesarios para determinar el valor de las parcelas.

Palabras clave: Capitalización de rentas, Expropiación Forzosa, Fincas Rústicas, Interés de créditos hipotecarios, Interés de la Deuda Pública, Ley del Suelo, Ordenación Territorial. reports, After the recognition of the affected areas and her environment, on the basis of information obtained well be of the own entity expropriator well of the autonomous county regulation in effect in the moment of the expropriation, or of the Spanish Law of the Soil of 8/2007 in what concerns the capture of decisions for the approach of the hypotheses of the his work.

Finally, they justify the rate of the interest rate used for the Capitalization of the agrarian revenues, on the basis of in force regulation or official studies, and the coefficient multiplier of the value of the same ones, according to the territorial models of lands situation with regard to an urban core, both necessary parameters to determine the value of the plots.

Key words: Capitalization of lands revenues, Spanish Law Necessary Expropriation, Rustic lands, Interest of mortgage loans, Interest of the National debt, Spanish Law of the Soil, Territorial Arrangement.

\section{PLANTEAMIENTO DE LA SITUACIÓN GENERADA POR LA EXPROPIACIÓN FORZOSA}

Con motivo del anuncio en el Boletín Oficial del Estado de fechas 8 de abril de 2009, subtramo N-601-León, y 24 de abril de 2009, subtramo Palanquinos-Onzonilla, de la expropiación forzosa de fincas en la provincia de León debido a las obras del Tren de Alta Velocidad, AVE, los propietarios de ochenta y dos fincas de los Ayuntamientos de Villanueva de las Manzanas, Santas Martas y Vega de Infanzones, solicitaron un estudio de valoración alternativo de las mismas, a quien suscribe este trabajo, para presentarlo, en forma de alegaciones individuales, al Jurado Provincial de Expropiación Forzosa de León, tal y como es su derecho, según la Ley de Expropiación Forzosa, LEF, y su Reglamento, parcialmente modificada por la Ley del Suelo 8/2007, con el fin de expresar su desacuerdo respecto a la oferta de la Entidad Expropiante.

Dichas obras están incluidas en la normativa de la Ley 39/2003 de 17 de noviembre del Sector Ferroviario, Capítulo II, sobre planificación, proyecto y construcción de Infraestructuras integrantes de la red ferroviaria de interés general, siendo aplicable a las mismas su 
artículo 153. Así, las obras se encuentran amparadas por lo establecido en los artículos 228,233 y 236.2 del Reglamento de la Ley de Ordenación de los Transportes Terrestres de 28 de septiembre de 1990 y resulta de aplicación el artículo 52 de la Ley Expropiación Forzosa de 16 de diciembre de 1954 y demás concordantes de su Reglamento de 26 de abril de 1957. son las siguientes:

Las discrepancias entre propietarios y entidad expropiante

- Los precios ofrecidos por la entidad son excesivamente bajos: Del orden de $1,50 € / \mathrm{m}^{2}$ para las fincas de regadío, $0,70 € / \mathrm{m}^{2}$ para las fincas de secano o que no se riegan, como en el caso de los aprovechamientos de árboles de ribera, y de $0,40 € / \mathrm{m}^{2}$ para los pastos.

- No se han tenido en cuenta el valor de las infraestructuras de regadío o los pozos y, en aquellos casos en que la expropiación es parcial, no se contempla su restauración/indemnización para garantizar el regadío.

- No se han tenido en cuenta las subvenciones que reciben los propietarios de la PAC (con fondos procedentes de la Política Agraria Comunitaria) bien por superficie de cultivo bien por cosecha o bien por agricultura ecológica.

- No se han tenido en cuenta los perjuicios generados por la expropiación parcial si bien se considera un demérito del $10 \%$ cuando la parte no expropiada de la finca queda subdividida en dos parcelas o más. No se ha tenido en cuenta, por lo tanto, si la explotación de la parte no expropiada resulta antieconómica.

\section{LAS FINCAS}

\section{SITUACIÓN, CARACTERÍSTICAS Y APROVECHAMIENTOS DE}

En cuanto a los usos del suelo, las fincas a valorar se encuentran definidas como de "labor regadío", "labor secano" o "árboles de ribera".

Toda la zona que nos ocupa se encuentra dentro de la comarca denominada "Esla-Campos", cuyos índices de regionalización productiva y de barbecho, propuestas por el RD 1026/2002, pudiéndose modificar en determinadas condiciones, son: 
Tabla 1: Índices de regionalización

\begin{tabular}{|c|c|c|c|c|c|}
\hline \multirow[t]{2}{*}{ Comarca } & \multirow[b]{2}{*}{ 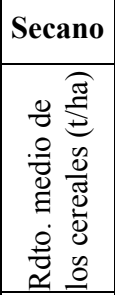 } & \multicolumn{3}{|c|}{ Regadío } & \multirow[b]{2}{*}{ 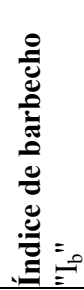 } \\
\hline & & 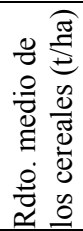 & 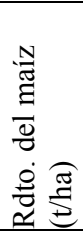 & 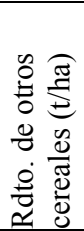 & \\
\hline Esla-Campos & 2,2 & 5,5 & 8,5 & 3,9 & 30 \\
\hline
\end{tabular}

En el caso de maíz de regadío, el rendimiento puede alcanzar $10 \mathrm{t} /$ ha y año habida cuenta de que las dos últimas campañas han sido catalogadas de "históricas" debido a los altos rendimientos obtenidos en las mismas.

Figura 1: Localización del área afectada

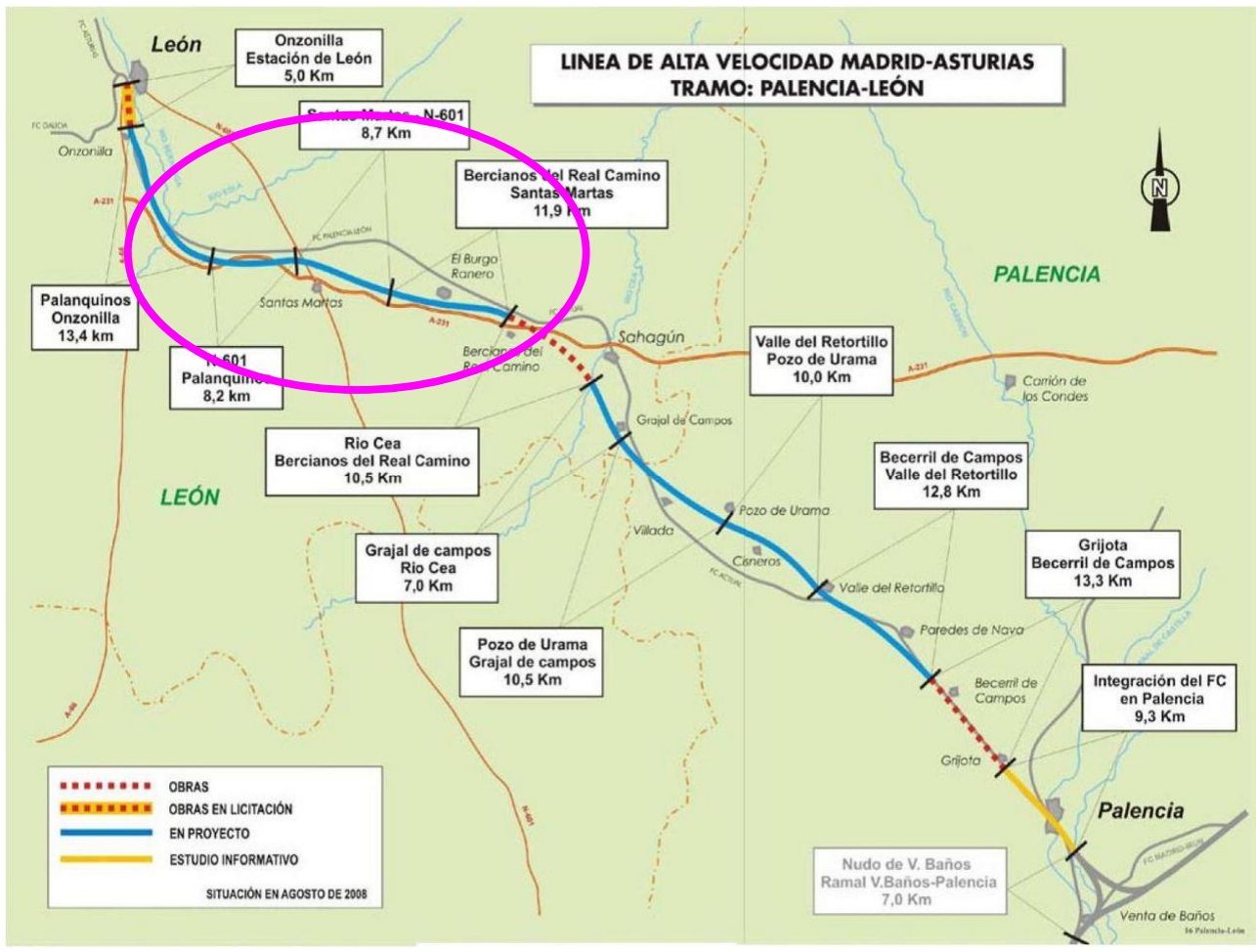

Fuente: Presidencia de Gobierno. 


\subsection{Climatología}

El clima responde en líneas generales al tipo continental, con inviernos largos y fríos, veranos cortos y calurosos, primaveras variables y otoños templados.

Las lluvias son escasas y los vientos de intensidad variable, según las estaciones suelen soplar del Oeste y del Noroeste.

La temperatura máxima absoluta es de $36^{\circ}$ y la temperatura mínima absoluta de $-13,8^{\circ}$.

Con 2.690 horas de sol anuales la zona se incluye dentro del grupo de insolación abundante.

El déficit medio de precipitación anual es de $306 \mathrm{~mm}$. El período de tormentas afecta principalmente a los meses de mayo, junio y julio, con una media anual en días de tormenta de 15,9.

Las nevadas se producen en los meses de diciembre, enero y febrero con una media anual de 8,5 días. El granizo no es frecuente, teniendo lugar ocasionalmente en marzo, abril y mayo, con 6,1 días de media anual.

Las heladas empiezan a primeros de noviembre y terminan a finales de abril, durando el período vegetativo medio 194 días.

\subsection{Topografía}

La zona se incluye dentro de la cuenca del río Esla, en su margen izquierda.

Las cotas más bajas están situadas en la ribera del río Esla con altitudes de 825 y 830 m sobre el nivel del mar.

Las terrazas constituyen los terrenos de aluvión que rodean al río Esla y sus afluentes, de gran valor agrícola y que han propiciado el asentamiento de núcleos de población.

La zona más rica se encuentra en los terrenos de cultivo situados en las riberas del río Esla, como se ha apuntado anteriormente. Son terrenos de regadío con aprovechamiento agrícola a base de cultivos de gran rendimiento. Abarcan los términos municipales de Villanueva de las Manzanas, Santas Martas y Vega de Infanzones. La riqueza agrícola de esta zona se debe precisamente a las infraestructuras de regadío que, en 
el caso de Villanueva de las Manzanas y Santas Martas está gestionada por la Comunidad de Regantes "Margen Izquierda del río Esla" y, en el caso de Vega de Infanzones, el riego se realiza por bombeo desde pozos artesianos de forma independiente por cada propietario.

\subsection{Fincas objeto de este trabajo}

Se presentan los datos de las fincas que han servido de base a este estudio y aunque están ordenadas por orden alfabético de los apellidos de los titulares de las mismas, se ha omitido este dato para garantizar su confidencialidad.

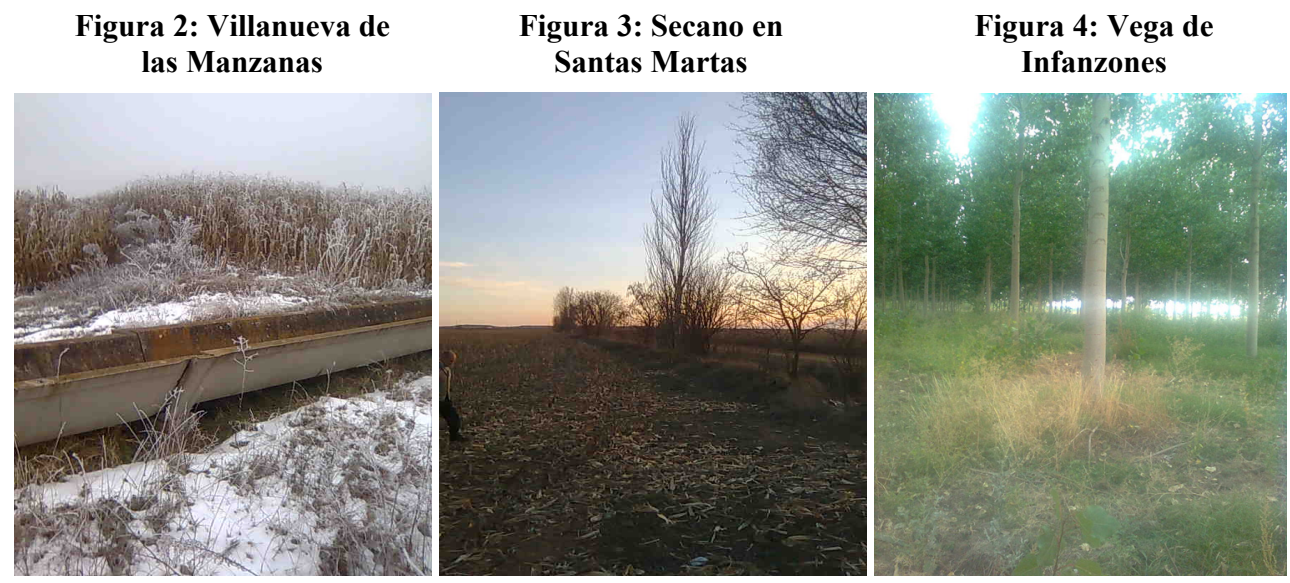

Figura 5: Finca de Regadío Santas Martas

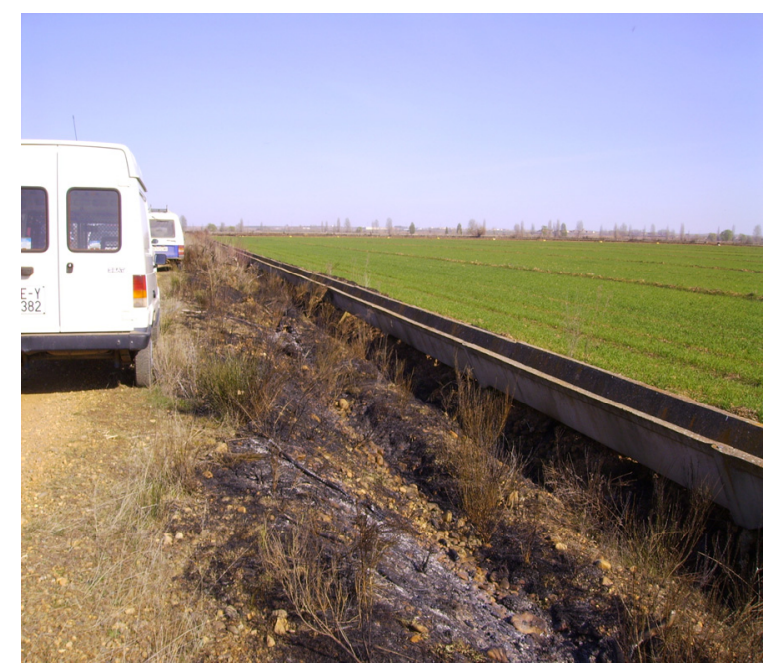

Figura 6: Regadío Vega de Infanzones

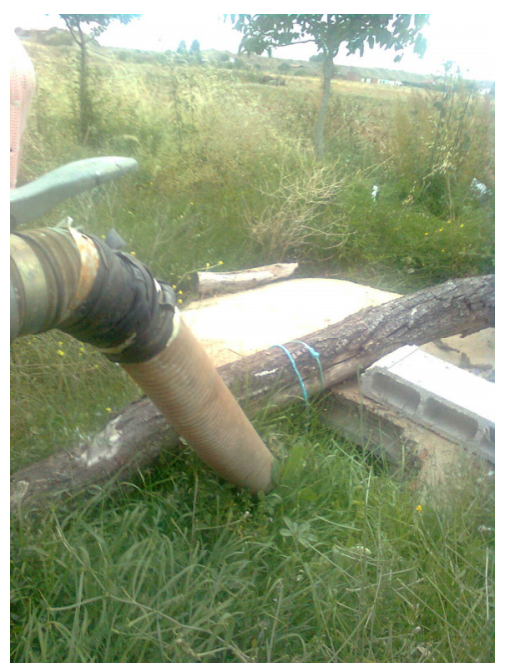


Tabla 2: Fincas correspondientes al Ayuntamiento de Santas Martas (Ramal N-601-Palanquinos)

\begin{tabular}{|c|c|c|c|c|c|c|c|}
\hline Finca & Polig. & Parcela & Labor & $\begin{array}{c}\text { Superficie } \\
\text { Total } \\
\mathbf{m}^{2} \\
\end{array}$ & $\begin{array}{c}\text { Superficie } \\
\text { Expropiada } \\
\mathbf{m}^{2} \\
\end{array}$ & División & $\begin{array}{c}\text { Ocupac. } \\
\text { Temp. } \\
\mathrm{m}^{2}\end{array}$ \\
\hline L-24.1605-0023 & 623 & 22 & Secano & 13.006 & 5.383 & Sí & 23 \\
\hline L-24.1605-0038 & 622 & 31 & Secano & 30.885 & 30.885 & - & - \\
\hline L-24.1605-0118 & 501 & 48 & Regadío & 27.770 & 27.770 & - & - \\
\hline L-24.1605-0006 & 623 & 36 & Secano & 8.035 & 4.328 & Sí & No \\
\hline L-24.1605-0060 & 502 & 59 & Regadío & 45.660 & 5.114 & No & No \\
\hline L-24.1605-0032 & 622 & 1 & Secano & 124.261 & 14.480 & Sí & No \\
\hline L-24.1605-0028 & 622 & 5522 & Secano/Pastos & 5.654 & 243 & No & No \\
\hline L-24.1605-0630 & 622 & 18 & Secano & 29.165 & 10.966 & Sí & No \\
\hline L-24.1605-0044 & 622 & 6 & $\begin{array}{l}\text { Secano, } \\
\text { agricul. ecológica }\end{array}$ & 64.240 & $\begin{array}{l}18.225 \text { con } 2 \\
\text { actas previas }\end{array}$ & Sí & 1.623 \\
\hline L-24.1605-0025 & 623 & 24 & Secano & 12.965 & 5.269 & No & No \\
\hline L-24.1605-0024 & 623 & 23 & Secano & 5.240 & 3.843 & Sí & No \\
\hline L-24.1605-0037 & 622 & 30 & Secano & 38.365 & 38.365 & - & - \\
\hline L-24.1605-0001 & 623 & 56 & Secano & 13.475 & 151 & No & No \\
\hline L-24.1605-0002 & 623 & 57 & Secano & 17.125 & 820 & No & No \\
\hline L-24.1605-0075 & 502 & 22 & Regadío & 35.195 & 12.720 & Sí & No \\
\hline L-24.1605-0042 & 622 & 8 & Secano & 16.994 & 16.994 & - & - \\
\hline L-24.1605-0095 & 501 & 61 & Regadío & 17.370 & 978 & No & No \\
\hline L-24.1605-0079 & 502 & 3 & Regadío & 159.270 & $\begin{array}{r}119.794 \\
\text { con arbolado }\end{array}$ & No & No \\
\hline L-24.1605-0100 & 501 & 55 & Regadío & 30.490 & 8.653 & No & No \\
\hline L-24.1605-0099 & 501 & 54 & Regadío & 20.500 & 4.408 & No & No \\
\hline L-24.1605-0006 & 623 & 33 & Secano & 4.247 & $\begin{array}{r}2.097 \\
\text { servidumbre } \\
\text { de } 81 \mathrm{~m}^{2} \\
\end{array}$ & Sí & 35 \\
\hline L-24.1605-0088 & 501 & 68 & Regadío & 6.340 & 807 & No & No \\
\hline L-24.1605-0087 & 501 & 69 & Regadío & 10.400 & 891 & No & No \\
\hline L-24.1605-0085 & 501 & 70 & Regadío & 1480 & 292 & No & No \\
\hline L-24.1605-0036 & 622 & 29 & Secano & 38.110 & 38.110 & - & - \\
\hline
\end{tabular}

Fuente: Actas previas de Ocupación y BOE.

Tabla 3: Fincas correspondientes al Ayuntamiento de Vega de Infanzones

\begin{tabular}{|l|c|c|l|r|r|c|}
\hline Finca & Polig. & Parcela & Labor & $\begin{array}{c}\text { Superficie } \\
\text { Total } \\
\mathbf{m}^{2}\end{array}$ & $\begin{array}{c}\text { Superficie } \\
\text { Expropiada } \\
\mathbf{m}^{2}\end{array}$ & $\begin{array}{c}\text { Elementos } \\
\text { añadidos }\end{array}$ \\
\hline Fincas correspondientes al ramal N-601-Palanquinos \\
\hline L-24.1973-0005 & 101 & 61 & Regadío & 8.490 & 8.490 & Sí \\
\hline L-24.1973-0004 & 101 & 62 & Regadío & 4.710 & 4.710 & Sí \\
\hline L-24.1973-0018 & 103 & 72 & Regadío & 25.500 & 25.500 & Sí \\
\hline L-24.1973-0011 & 103 & 73 & Regadío & 1.270 & 1.270 & Sí \\
\hline L-24.1973-0014 & 103 & 76 & Regadío & 6.730 & 6.730 & Sí \\
\hline
\end{tabular}




\begin{tabular}{|c|c|c|c|c|c|c|}
\hline L-24.1973-0012 & 103 & 78 & Regadío & 8.730 & 8.730 & Sí \\
\hline L-24.1973-0011 & 103 & 81 & Regadío & 11.640 & 11.640 & Sí \\
\hline L-24.1973-0010 & 103 & 82 & Regadío & 20.520 & 20.520 & Sí \\
\hline L-24.1973-0023 & 103 & 177 & Regadío & 5.110 & 5.110 & Sí \\
\hline L-24.1973-0025 & 103 & 179 & Regadío & 5.780 & 5.780 & Sí \\
\hline L-24.1973-0030 & 103 & 184 & Regadío & 6.529 & 6.529 & Sí \\
\hline L-24.1973-0031 & 103 & 193 & Regadío & 16.240 & 16.240 & Sí \\
\hline L-24.1973-0032 & 103 & 194 & Regadío & 4.590 & 4.590 & Sí \\
\hline L-24.1973-0047 & 103 & 195 & Regadío & 5.390 & 5.390 & No \\
\hline L-24.1973-0036 & 103 & 198 & Regadío & 13.126 & 13.126 & Sí \\
\hline L-24.1973-0037 & 103 & 199 & Regadío & 7.200 & 7.200 & Sí \\
\hline L-24.1973-0041 & 103 & 203 & Regadío & 10.370 & 10.370 & Sí \\
\hline L-24.1973-0044 & 103 & 206 & Regadío & 5.710 & 5.710 & No \\
\hline L-24.1973-0045 & 103 & 207 & Regadío & 12.980 & 12.980 & Sí \\
\hline L-24.1973-0047 & 103 & 209 & Regadío & 9.140 & 9.140 & Sí \\
\hline L-24.1973-0048 & 103 & 210 & Árboles de Ribera & 6.620 & 6.620 & Sí \\
\hline L-24.1973-0008 & 103 & 86 & Secano & 14.010 & 10.284 & No \\
\hline L-24.1973-0003 & 101 & 63 & Secano & 2930 & 2930 & No \\
\hline L-24.1973-0002 & 101 & 64 & Secano & 4.490 & 4.490 & No \\
\hline L-24.1973-0001 & 101 & 65 & Secano & 4.200 & 4.200 & No \\
\hline L-24.1973-0016 & 103 & 74 & Secano & 3.140 & 3.140 & No \\
\hline L-24.1973-0013 & 103 & 77 & Secano & 5.730 & 5.730 & No \\
\hline L-24.1973-0019 & 103 & 173 & Secano & 10.470 & 10.470 & Sí \\
\hline L-24.1973-0021 & 103 & 175 & Secano & 5.850 & 5.850 & No \\
\hline L-24.1973-0022 & 103 & 176 & Secano & 3.380 & 3.380 & No \\
\hline L-24.1973-0024 & 103 & 178 & Secano & 9.660 & 9.660 & No \\
\hline L-24.1973-0026 & 103 & 180 & Secano & 2.700 & 2.700 & No \\
\hline L-24.1973-0035 & 103 & 197 & Secano & 7.580 & 7.580 & Sí \\
\hline L-24.1973-0046 & 103 & 208 & Secano & 2.590 & 2.590 & No \\
\hline \multicolumn{7}{|c|}{ Fincas correspondientes al ramal Palanquinos-Onzonilla } \\
\hline L-24.1974-0178 & 103 & 17 & Regadío & 18.171 & $\begin{array}{r}7.168 \\
\text { con división } \\
\text { y ocupación } \\
\text { temporal de } \\
492 \mathrm{~m}^{2}\end{array}$ & No \\
\hline L-24.1974-0264 & 108 & 16 & Regadío & 25.040 & $\begin{array}{r}8.698 \\
\text { con división }\end{array}$ & No \\
\hline L-24.1974-0246 & 108 & 108 & Regadío & 26.590 & 26.308 & Sí \\
\hline L-24.1974-0245 & 108 & 107 & Regadío/huerta & 590 & 590 & No \\
\hline L-24.1974-0102 & 101 & 4 & Árboles de Ribera & 9.301 & 3.819 & No \\
\hline L-24.1974-0115 & 101 & 58 & Árboles de Ribera & 109.680 & $\begin{array}{r}20.080 \\
\text { con división }\end{array}$ & No \\
\hline L-24.1974-0135 & 103 & 86 & Secano & 14.010 & 2.053 & No \\
\hline L-24.1974-0020 & 103 & 174 & Regadío & 9.300 & 9.300 & Sí \\
\hline
\end{tabular}

Fuente: Actas previas de Ocupación y BOE. 
Tabla 4: Fincas correspondientes al Ayuntamiento de Villanueva de las Manzanas (Regadío con infraestructura de riego en todas las fincas)

Ramal N-601-Palanquinos

\begin{tabular}{|c|c|c|c|c|c|c|}
\hline Finca & Polig. & Parcela & $\begin{array}{c}\text { Superficie } \\
\text { Total } \\
\mathbf{m}^{2} \\
\end{array}$ & $\begin{array}{c}\text { Superficie } \\
\text { Expropiada } \\
\mathbf{m}^{2} \\
\end{array}$ & División & $\begin{array}{c}\text { Ocupac. } \\
\text { Temp. } \\
\text { m }^{2}\end{array}$ \\
\hline L-24.2186.0038 & 110 & 29 & 16.680 & 4 & No & No \\
\hline L-24.2186.0032 & 110 & 32 & 44.575 & 6.968 & Sí & No \\
\hline L-24.2186.0067 & 109 & 10 & 46.085 & 14.887 & Sí & 563 \\
\hline L-24.2186.0030 & 110 & 14 & 50.245 & 3.949 & No & No \\
\hline L-24.2186.0041 & 110 & 20 & 10.500 & 1.985 & No & No \\
\hline L-24.2186.0028 & 110 & 34 & 30.425 & 14.635 & Sí & No \\
\hline L-24.2186.0046 & 110 & 28 & 14.679 & 14.679 & - & - \\
\hline L-24.2186.0031 & 110 & 33 & 57.840 & 18.824 & No & No \\
\hline L-24.2186.0037 & 110 & 30 & 16.680 & 60 & No & No \\
\hline L-24.2186.0036 & 110 & 31 & 18.565 & 1.073 & No & No \\
\hline L-24.2186.0012 & 111 & 10013 & 25.903 & 5.978 & Sí & No \\
\hline L-24.2186.0011 & 111 & 13 & 35.902 & 8.956 & Sí & No \\
\hline L-24.2186.0023 & 111 & 6 & 135.880 & 2.542 & Sí & 89 \\
\hline L-24.2186.0006 & 111 & 15 & 150.170 & 44.268 & No & 204 \\
\hline L-24.2186.0069 & 109 & 9 & 34.772 & 5.237 & Sí & No \\
\hline $\begin{array}{l}\mathrm{L}-24.2186 .0069-\mathrm{C} 01 \\
\left(2^{\mathrm{a}} \text { Expropiación }\right)\end{array}$ & 109 & 9 & 34.772 & 3.593 & No & No \\
\hline
\end{tabular}

Fuentes: Actas previas de Ocupación y BOE.

\section{CRITERIOS DE VALORACIÓN}

En el caso de valoración agraria a efectos de expropiación forzosa, hay que aplicar el "Principio de Finalidad" por el cual deben tasarse, además del terreno y sus producciones, los bienes inmuebles, daños, lucro cesante, etc. Se van a tener en cuenta los siguientes aspectos:

- Perjuicios causados por expropiación parcial:

Se producen por la reducción del valor de la superficie que queda para el expropiado tras el procedimiento. Son debidos a la disminución de superficie y a la pérdida de forma, recorridos más largos, maniobras complicadas y difíciles de la maquinaria, etc. Se plantean problemas de sobredimensionamiento de los medios de producción, afectan a los costes unitarios de las labores, dificultan el mantenimiento de las alternativas de los cultivos. 
Se utilizará un coeficiente del $30 \%$ con el que se incrementará el valor de la superficie no expropiada, puesto que es el incremento estimado de los costes unitarios de explotación debido a que, al tratarse de una infraestructura lineal que tiene en cuenta el mejor trazado para la propia obra, genera fuertes asimetrías en las parcelas. Por otro lado, si la superficie no expropiada queda dividida en dos subparcelas, el demérito que se reconoce, según la entidad expropiante, es de un 10\% que, en esta valoración, incrementará el valor de la superficie no expropiada, caso de sufrir subdivisión.

Se adjunta tabla de sentencias del Tribunal Supremo referente a este aspecto.

De su lectura se desprende lo reducido e insuficiente que resulta el coeficiente de demérito ofrecido por la entidad expropiante.

Tabla 5: Porcentajes de indemnizaciones por expropiaciones.

Sentencias del Tribunal Supremo, en base al art. 46 de la L.E.F.

\begin{tabular}{|c|c|c|c|}
\hline $\begin{array}{l}\text { Sentencia } \\
\text { Trubunal } \\
\text { Supremo }\end{array}$ & $\begin{array}{l}\text { Superficie } \\
\text { "Restos" }\end{array}$ & $\begin{array}{c}\text { Porcentaje } \\
\text { indemnización }\end{array}$ & Comentarios \\
\hline $22 / 03 / 1993$ & $5.385,00 \mathrm{~m}^{2}$ & $25,00 \%$ & $\begin{array}{l}\text { El perito judicial estima el porcentaje en el } \\
100 \% \text { mientras que la demandante en el } 25 \% \\
\text { por lo que, en aras de la congruencia con lo } \\
\text { pedido el T.S. lo fija en el } 25 \% \text {. }\end{array}$ \\
\hline $16 / 11 / 1984$ & $1.866,00 \mathrm{~m}^{2}$ & $25,00 \%$ & $\begin{array}{l}\text { El T.S. acepta el aprovechamiento del resto } \\
\text { sin ningún valor económico. }\end{array}$ \\
\hline $19 / 11 / 1997$ & $5.295,44 \mathrm{~m}^{2}$ & $25,00 \%$ & Dos restos: $2.837,38 \mathrm{~m}^{2}$ y $2.458,06 \mathrm{~m}^{2}$ \\
\hline $19 / 11 / 1997$ & $4.995,24 \mathrm{~m}^{2}$ & $25,00 \%$ & Dos restos: $2.125,47 \mathrm{~m}^{2}$ y $2.869,50 \mathrm{~m}^{2}$ \\
\hline $20 / 04 / 1983$ & $55,50 \mathrm{~m}^{2}$ & $50,00 \%$ & Suelo urbano. \\
\hline $12 / 12 / 1984$ & $100,00 \mathrm{~m}^{2}$ & $90,00 \%$ & Suelo urbano. \\
\hline $15 / 05 / 2001$ & $428.00 \mathrm{~m}^{2}$ & $30,00 \%$ & \\
\hline $26 / 03 / 1994$ & $1.274,030 \mathrm{~m}^{2}$ & $15,00 \%$ & $\begin{array}{l}\text { Sobre la superficie expropiada y no sobre } \\
\text { restos. EL T.S. considera que debe ser sobre } \\
\text { los restos, pero al solicitar tanto el apelante } \\
\text { como el perito judicial sobre lo expropiado, } \\
\text { el T.S. lo acepta. En otro orden de cosas se } \\
\text { expropian } 127,4030 \text { hectáreas, de las } 925 \\
\text { que, al parecer, tenia la finca. }\end{array}$ \\
\hline $09 / 04 / 1994$ & $4.430 .00 \mathrm{~m}^{2}$ & $40.00 \%$ & Se expropian $3.528,00 \mathrm{~m}^{2}$ \\
\hline $09 / 04: 1994$ & $7.398 .00 \mathrm{~m}^{2}$ & $15.00 \%$ & Se expropian $4.722,00 \mathrm{~m}^{2}$ \\
\hline $09 / 04 / 1994$ & $7.700 .00 \mathrm{~m}$ & $20.00 \%$ & Se expropian $6.718,00 \mathrm{~m}^{2}$. \\
\hline $09,04 ! 1994$ & $19,500.00 \mathrm{~m}$ & $5.00 \%$ & Se expropian $2.140,00 \mathrm{~m}^{2}$ \\
\hline $09 / 04 / 1994$ & $320.00 \mathrm{~m}$ & $80.00 \%$ & Se expropian $1.625,00 \mathrm{~m}^{*}$ \\
\hline $09 / 04 / 1994$ & $29.890,00 \mathrm{~m}^{2}$ & $2,00 \%$ & Se expropian $5.958,00 \mathrm{~m}^{2}$. \\
\hline $28 / 10 / 1995$ & $228,00 \mathrm{~m}^{2}$ & $80,00 \%$ & Se expropian $3.622,00 \mathrm{~m}^{2}$ \\
\hline
\end{tabular}

Fuente: J.L. Pérez-Salas Sagreras (2005). 
- Perjuicios causados por la rápida ocupación:

Son inherentes al procedimiento de expropiación forzosa. El valor dado a este perjuicio equivale al importe de los gastos hasta el momento de la desposesión y al beneficio perdido al no recoger las cosechas pendientes, si las hubiera.

La entidad expropiante ofrece $0,10 € / \mathrm{m}^{2}$ en regadío y $0,05 € / \mathrm{m}^{2}$ en secano por este concepto.

- Perjuicios derivados de la posible escasez de suelo cultivable en los "restos" después de la expropiación:

Se han de considerar todas aquellas disminuciones de superficie a causa de la expropiación que afecten al régimen de las unidades mínimas de cultivo.

- Perjuicios derivados de las subvenciones perdidas:

Se han tenido en cuenta las subvenciones de la PAC a las que las fincas tenían derecho en el momento de la expropiación.

- Perjuicios derivados del desmantelamiento de las infraestructuras de regadío:

La infraestructura de regadío forma parte inherente de las fincas y este perjuicio se va a estimar como el coste medio de las obras que fue necesario acometer en su día y, tal como consta en las cuentas de la Comunidad de regantes, su importe fue de $3.000 € /$ ha aplicada a toda la superficie de la finca a expropiar. Esta estimación se va a utilizar tanto como un valor añadido de las fincas como la estimación del coste de reparación de la infraestructura no expropiada tal y como se especifica más adelante.

- Perjuicios causados por una ocupación temporal:

Se valorarán por los beneficios que se dejaron de percibir en el periodo de la ocupación y las posibles labores para recuperar el terreno a la situación inicial. Así que se considerará el $8 \%$ de los ingresos (Beneficio máximo porque se considera dentro de este valor las obras iniciales de recuperación del terreno que se debería haber obtenido durante el tiempo de ocupación) más los gastos. $\mathrm{El}$ tiempo de ocupación será de dos años según las hojas de aprecio consultadas. 
- Costes de reposición de los elementos expropiados o destruidos como consecuencia de la expropiación:

Dentro de este apartado se incluyen las obras para reponer la infraestructura de regadío allí donde las obras hagan imposible acceder a las acequias de riego así como la posibilidad de drenaje. Se estimarán en $3.000 € /$ ha aplicada a la superficie no expropiada de las fincas que riegan con acequia, caso de los regadíos de Santas Martas y Villanueva de las Manzanas. En el caso de Vega de Infanzones, que riegan con pozos artesianos y sufren expropiación total, no hay nada que reponer.

- Costes originados por el proceso de expropiación:

En este apartado se incluyen aquellos gastos en los que incurre el expropiado en la defensa de sus intereses, tales como los honorarios por asesoramiento técnico o jurídico. Se va a estimar como un $10 \%$ del incremento del valor de la finca calculado en este informe respecto al valor ofrecido por la entidad expropiante.

\section{MÉTODOS DE VALORACIÓN POR CAPITALIZACIÓN DE RENTAS}

El método Analítico de Capitalización de Rentas plantea algunas debilidades, como la de particionar el binomio Renta+Beneficio en las partes adecuadas y la complejidad para determinar el tipo exacto de capitalización.

Para determinar la parte correspondiente a la renta, se suelen utilizar dos hipótesis diferentes:

- Suponer que el beneficio representa un porcentaje de la diferencia entre ingresos y gastos, que para el caso que nos ocupa, se sitúa en torno al 40\% (para un beneficio del 60\%).

- Suponer que el beneficio representa entre un $6 \%$ y un $8 \%$ de la producción final anual (en este caso, los ingresos).

Por lo tanto, se va a calcular cada hipótesis por separado, para determinar los valores máximos y mínimos de renta.

Se considera, además, que tanto los ingresos como los gastos tienen el mismo tipo de interés o coste de oportunidad de las 
inversiones alternativas corregido de los efectos de plusvalía, inflación general del sistema económico, inflación de ingresos y gastos, etc.

En cuanto a la tasa de capitalización, se debe utilizar la tasa de capitalización al tipo de interés de la Deuda Pública a tres años, debidamente justificada, que es necesario utilizar si se quiere aplicar la Ley del Suelo. En este informe se calcula en torno al 4\%, a partir de los datos obtenidos de los informes emitidos por el Banco de España para los años de 2004-2008, si bien el anuncio de las Actas Previas de Ocupación se publicó en abril de 2009.

Figura 7: Evolución de los tipos de Deuda Pública

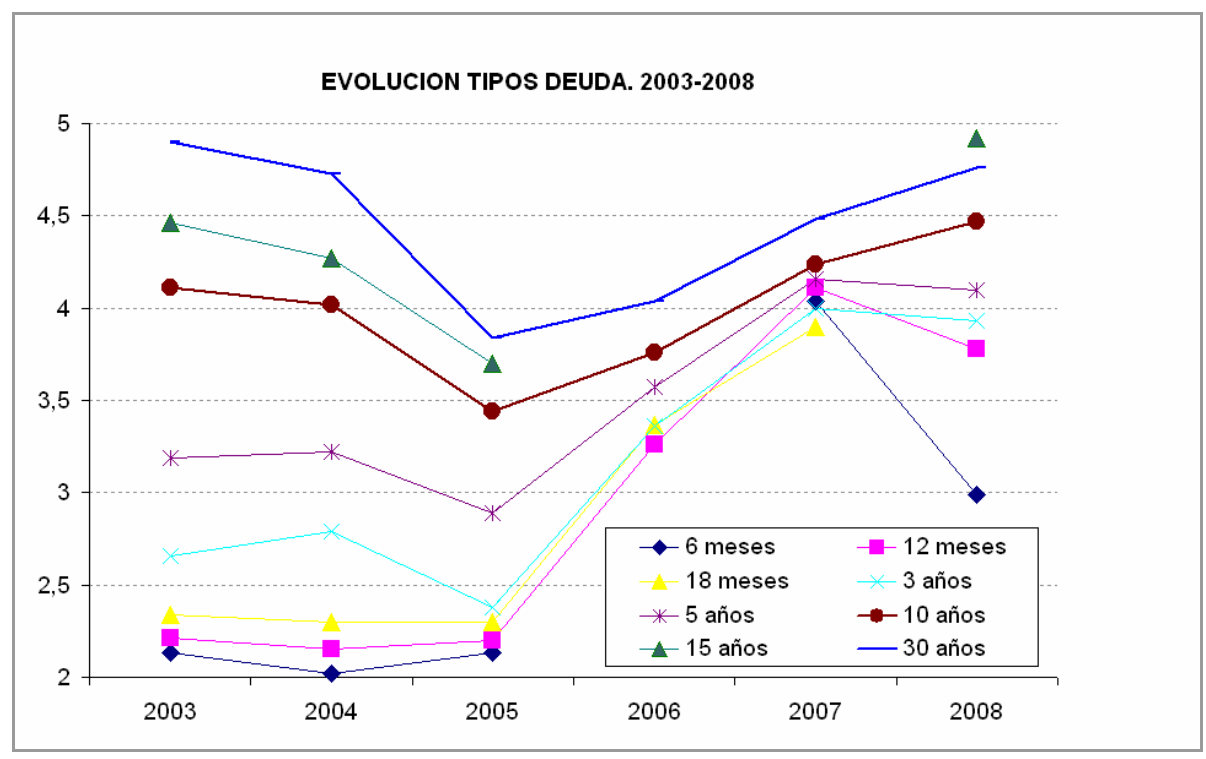

Fuente: Banco de España.

Por lo tanto, para el cálculo del valor unitario medio de la finca, se tomarán en consideración ambos supuestos y se elegirá el menor de los dos valores, tal y como se exige en la normativa vigente de valoración de bienes inmuebles. Se considera un $5 \%$ por afección en todos los casos.

Una vez aplicado el método de Capitalización de Rentas, tomando como referencia la Deuda Pública a tres años, se procederá a establecer el Valor Expropiatorio del Suelo Rural, según la Ley del Suelo de $8 / 2007$, mediante la aplicación de un coeficiente de mayoración en base a la localización espacial de las fincas respecto a un núcleo urbano 
desde el punto de vista del modelo regional de Desarrollo Rural en la Ordenación del territorio.

\section{CÁLCULO DE VALORES TÉCNICOS}

Se va a proceder al cálculo de ingresos y gastos de explotación lo que va a permitir determinar el conjunto de renta y beneficio en los terrenos calificados como "Labor regadío", "Labor secano" y "Árboles de Ribera".

En el caso de árboles de ribera, se va a utilizar el caso de una plantación de cinco años que es el caso de dos de las tres plantaciones valoradas.

\subsection{Valores técnicos para terrenos de "Labor regadío"}

Hay que tener en cuenta las ayudas al sector según lo especificado en el Reglamento CE $n^{\circ} 1234 / 2007$, en vigor en el momento del anuncio de la expropiación en abril de 2009, que viene a ser, si se cultiva la tierra, de $63 € / t$. Cuestión que se ha comprobado en las visitas a la zona finca por finca.

En el regadío se deja habitualmente una alternativa de Cereal de invierno (regadío)/Maíz.

Tabla 6: Ingresos por hectárea en regadío

\begin{tabular}{|c|c|c|c|c|c|}
\hline \multirow[t]{2}{*}{ Productos } & \multicolumn{2}{|c|}{ Ayudas } & \multirow{2}{*}{$\begin{array}{c}\text { Rendimiento } \\
\text { (kg/ha) }\end{array}$} & \multirow{2}{*}{$\begin{array}{l}\text { Precio } \\
(€ / \text { kg) }\end{array}$} & \multirow{2}{*}{$\begin{array}{c}\text { Ingresos } \\
(€ / \mathbf{h a})\end{array}$} \\
\hline & $(€ / t)$ & (€/ha) & & & \\
\hline Cereal de Invierno (regadío) & 63 & 157,7 & 5.500 & 0,200 & $1.100,00$ \\
\hline Maíz & 63 & 157,5 & 10.000 & 0,204 & $2.197,70$ \\
\hline \multicolumn{5}{|c|}{ Ingresos totales anuales $(€ / \mathrm{ha})=$} & $3.297,70$ \\
\hline
\end{tabular}

Tabla 7: Gastos por hectárea en regadío

\begin{tabular}{|c|c|}
\hline Concepto & Gastos (€/ha) \\
\hline Mano de obra (Tractorista, peón, etc.) & 350,00 \\
\hline Materias primas & 95,00 \\
\hline Maquinaria & 160,00 \\
\hline Interés del capital circulante, Contribuciones e impuestos & 20,80 \\
\hline Gastos totales anuales $(€ / \mathrm{ha})$ & 635,80 \\
\hline
\end{tabular}


La diferencia entre ingresos y gastos es: I - $\mathrm{G}=2.661,19 € / \mathrm{ha}$

Se tiene:

Tabla 8: Capitalización de rentas en regadío

\begin{tabular}{|l|c|c|c|c|}
\hline \multicolumn{1}{|c|}{ Hipótesis de cálculo } & $\begin{array}{c}\text { Renta en } \\
\boldsymbol{\epsilon} / \mathbf{h a}\end{array}$ & $\begin{array}{c}\text { Tasa de } \\
\text { capitalización }\end{array}$ & $\begin{array}{c}\text { Valor en } \\
\mathbf{\epsilon} / \mathbf{h a}\end{array}$ & $\begin{array}{c}\text { Valor con } \\
\text { afección del } \\
\mathbf{5 \%} \text { en } \boldsymbol{\epsilon} / \mathbf{h a}\end{array}$ \\
\hline $\begin{array}{l}\mathrm{R}=0,4(\mathrm{I}-\mathrm{G}) \\
\text { (Renta mínima) }\end{array}$ & $1.064,48$ & 4,00 & $26.612,00$ & $27.942,60$ \\
\hline $\begin{array}{l}\mathrm{R}=\mathrm{I}-\mathrm{G}-\mathrm{B} \text { con } \mathrm{B}=0,07 \times \mathrm{I} \\
\text { (Renta máxima) }\end{array}$ & $2.430,35$ & 4,00 & $60.758,75$ & $63.796,69$ \\
\hline Media & $1.747,42$ & & & $45.869,78$ \\
\hline
\end{tabular}

\subsection{Cálculo de valores técnicos para las fincas de "Labor}

secano"

Se va a proceder al cálculo de ingresos y gastos de explotación lo que va a permitir determinar el conjunto de renta y beneficio en los terrenos calificados como "Labor secano".

En el secano se deja habitualmente una alternativa de año y vez y se trata de Trigo/Cebada y, además hay que tener en cuenta las ayudas al sector según lo especificado en el Reglamento CE $n^{\circ} 1234 / 2007$, que viene a ser, si se cultiva la tierra, de $63 € / \mathrm{t}$ :

Tabla 9: Ingresos por hectárea en secano

\begin{tabular}{|c|c|c|c|c|c|}
\hline \multirow[t]{2}{*}{ Productos } & \multicolumn{2}{|c|}{ Ayudas } & \multirow{2}{*}{$\begin{array}{c}\text { Rendimiento } \\
(\mathrm{kg} / \mathrm{ha})\end{array}$} & \multirow{2}{*}{$\begin{array}{c}\text { Precio } \\
\text { productos } \\
(€ / \mathbf{k g})\end{array}$} & \multirow{2}{*}{$\begin{array}{r}\text { Ingresos } \\
\text { totales } \\
\text { (€/ha) }\end{array}$} \\
\hline & $(€ / t)$ & (€/ha) & & & \\
\hline Trigo & 63 & 157,7 & 2.500 & 0,200 & 657,7 \\
\hline Cebada & 63 & 157,5 & 2.500 & 0,200 & 657,7 \\
\hline
\end{tabular}

Tabla 10: Gastos por hectárea en secano

\begin{tabular}{|c|c|}
\hline Concepto & Gastos (€/ha) \\
\hline Mano de obra (Tractorista, peón, etc.) & 90,00 \\
\hline Materias primas & 25,00 \\
\hline Maquinaria & 40,00 \\
\hline Interés del capital circulante, Contribuciones e impuestos & 8,60 \\
\hline Gastos totales anuales $(€ /$ ha) & 163,60 \\
\hline
\end{tabular}

$$
I-G=1.151,80 € / h a
$$


Tabla 11: Capitalización de rentas en secano

\begin{tabular}{|l|c|c|c|c|}
\hline \multicolumn{1}{|c|}{ Hipótesis de cálculo } & $\begin{array}{c}\text { Renta en } \\
\boldsymbol{\epsilon} / \mathbf{h a}\end{array}$ & $\begin{array}{c}\text { Tasa de } \\
\text { capitalización }\end{array}$ & $\begin{array}{c}\text { Valor en } \\
\mathbf{\epsilon} / \mathbf{h a}\end{array}$ & $\begin{array}{c}\text { Valor con } \\
\text { afección del } \\
\mathbf{5 \%} \mathbf{e n} \boldsymbol{\epsilon} / \mathbf{h a}\end{array}$ \\
\hline $\begin{array}{l}\mathrm{R}=0,5(\mathrm{I}-\mathrm{G}) \\
\text { (Renta mínima) }\end{array}$ & 575,90 & 4,00 & $14.397,50$ & $15.117,38$ \\
\hline $\begin{array}{l}\mathrm{R}=\mathrm{I}-\mathrm{G}-\mathrm{B} \text { con } \mathrm{B}=0,07 \times \mathrm{I} \\
\text { (Renta máxima) }\end{array}$ & $1.243,88$ & 4,00 & $31.097,00$ & $32.651,85$ \\
\hline Media & 909,89 & & & $23.861,25$ \\
\hline
\end{tabular}

5.3. Cálculo de valores técnicos por el método de capitalización de rentas para "Árboles de Ribera"

Se va a proceder a estimar los ingresos y calcular los gastos de explotación lo que va a permitir determinar el conjunto de renta y beneficio en los terrenos calificados como "Labor árboles de ribera" en el quinto año de la plantación. Hay que tener en cuenta las ayudas al sector según lo especificado en el Reglamento CE n 1234/2007.

Tabla 12: Ingresos por hectárea y año en "árboles de ribera"

\begin{tabular}{|l|c|c|c|c|}
\hline \multirow{2}{*}{ Productos } & \multicolumn{2}{|c|}{ Ayudas $\mathbf{\epsilon} / \mathbf{h a}$} & $\begin{array}{c}\text { Valor } \\
\text { arbolado } \\
\mathbf{\epsilon} / \mathbf{h a}\end{array}$ & $\begin{array}{c}\text { Ingresos } \\
\text { (€/ha) }\end{array}$ \\
\cline { 2 - 4 } & $\begin{array}{c}\text { Costes de } \\
\text { mantenimiento }\end{array}$ & $\begin{array}{c}\text { Primas } \\
\text { compensatorias }\end{array}$ & & \\
\hline $\begin{array}{l}\text { Árboles de Ribera } \\
\text { por forestación de } \\
\text { tierras de regadío, } \\
\begin{array}{l}\text { con marco de } \\
\text { plantación de } 6 \times 6\end{array}\end{array}$ & 288,49 & 324,55 & $2.431,00$ & $3.044,03$ \\
\hline
\end{tabular}

Tabla 13: Gastos por hectárea al $5^{\circ}$ año "Árboles de ribera"

\begin{tabular}{|c|c|}
\hline Concepto & Gastos (€/ha) \\
\hline Mano de obra en poda y otras labores de plantación (Tractorista, peón, etc.) & 350,00 \\
\hline Materias primas & 95,00 \\
\hline Maquinaria & 160,00 \\
\hline Interés del capital circulante, Contribuciones e impuestos & 20,80 \\
\hline Gastos totales anuales $(€ / \mathrm{ha})$ & 635,80 \\
\hline
\end{tabular}

La diferencia entre ingresos y gastos es: I - $G=2.408,23 € /$ ha 
Tabla 14: Capitalización de rentas "Árboles de ribera"

\begin{tabular}{|l|c|c|c|c|}
\hline \multicolumn{1}{|c|}{ Hipótesis de cálculo } & $\begin{array}{c}\text { Renta en } \\
\boldsymbol{\epsilon} / \mathbf{h a}\end{array}$ & $\begin{array}{c}\text { Tasa de } \\
\text { capitalización }\end{array}$ & $\begin{array}{c}\text { Valor en } \\
\boldsymbol{\epsilon} / \mathbf{h a}\end{array}$ & $\begin{array}{c}\text { Valor con } \\
\text { afección del } \\
\mathbf{5 \%} \mathbf{e n} \mathbf{\epsilon} / \mathbf{h a}\end{array}$ \\
\hline $\begin{array}{l}\mathrm{R}=0,4(\mathrm{I}-\mathrm{G}) \\
\text { (Renta mínima) }\end{array}$ & 963,29 & 4,00 & $24.082,25$ & $25.286,36$ \\
\hline $\begin{array}{l}\mathrm{R}=\mathrm{I}-\mathrm{G}-\mathrm{B} \text { con } \mathrm{B}=0,07 \times \mathrm{I} \\
\text { (Renta máxima) }\end{array}$ & $2.195,15$ & 4,00 & $54.878,75$ & $57.622,69$ \\
\hline Media & $1.579,22$ & & & $41.454,53$ \\
\hline
\end{tabular}

\section{CÁLCULO DE VALORES TÉCNICOS POR EL MÉTODO DE} CAPITALIZACIÓN POR POSICIÓN RESPECTO A NÚCLEO URBANO (COMO complemento al método de capitalización de rentas en fincas rústicas)

Según la Ley del Suelo $8 / 2007$, se puede utilizar un coeficiente de ponderación en función de la proximidad del suelo rústico a núcleo urbano desde 1 (Suelo en zona absolutamente rural) hasta un máximo de 2 (Suelo en zona limítrofe respecto al núcleo urbano), siempre y cuando se haya aplicado el método de capitalización de rentas con una tasa de interés correspondiente al tipo de interés de la Deuda Pública a tres años y se establece el abandono del método de comparación para la determinación del valor expropiatorio de las fincas en base a la siguiente justificación, que se cita textualmente:

En el suelo rural, se abandona el método de comparación porque muy pocas veces concurren los requisitos necesarios para asegurar su objetividad y la eliminación de elementos especulativos, para lo que se adopta el método asimismo habitual de la capitalización de rentas pero sin olvidar que, sin considerar las expectativas urbanísticas, la localización influye en el valor de este suelo, siendo la renta de posición un factor relevante en la formación tradicional del precio de la tierra. En el suelo urbanizado, los criterios de valoración que se establecen dan lugar a tasaciones siempre actualizadas de los inmuebles, que no aseguraba el régimen anterior. En todo caso y con independencia del valor del suelo, cuando éste está sometido a una transformación urbanizadora o edificatoria, se indemnizan los gastos e inversiones acometidos junto con una prima razonable que retribuya el riesgo asumido y se evitan saltos valorativos difícilmente entendibles en el curso del proceso de ordenación y ejecución urbanísticas. En los casos en los que una decisión administrativa impide 


\begin{abstract}
participar en la ejecución de una actuación de urbanización, o altera las condiciones de ésta, sin que medie incumplimiento por parte de los propietarios, se valora la privación de dicha facultad en sí misma, lo que contribuye a un tratamiento más ponderado de la situación en la que se encuentran aquéllos. En definitiva, un régimen que, sin valorar expectativas generadas exclusivamente por la actividad administrativa de ordenación de los usos del suelo, retribuye e incentiva la actividad urbanizadora o edificatoria emprendida en cumplimiento de aquélla y de la función social de la propiedad [Párrafo $4^{\circ}$ del apartado $\mathrm{V}$ de la "exposición de motivos" de la Ley 8/2007, de 28 de mayo, del Suelo. BOE $n^{\circ} 128$, de 29 de mayo de 2007].
\end{abstract}

El modelo regional de Desarrollo de zonas rurales respecto a su posicionamiento en relación a un núcleo urbano principal (Gómez Orea 2007), ha sido resumido y esquematizado (elaboración propia de las figuras) para explicar la toma de decisiones respecto al coeficiente utilizado en función de los defectos definidos para cada zona.

Figura 8: Concepto de Ordenación territorial

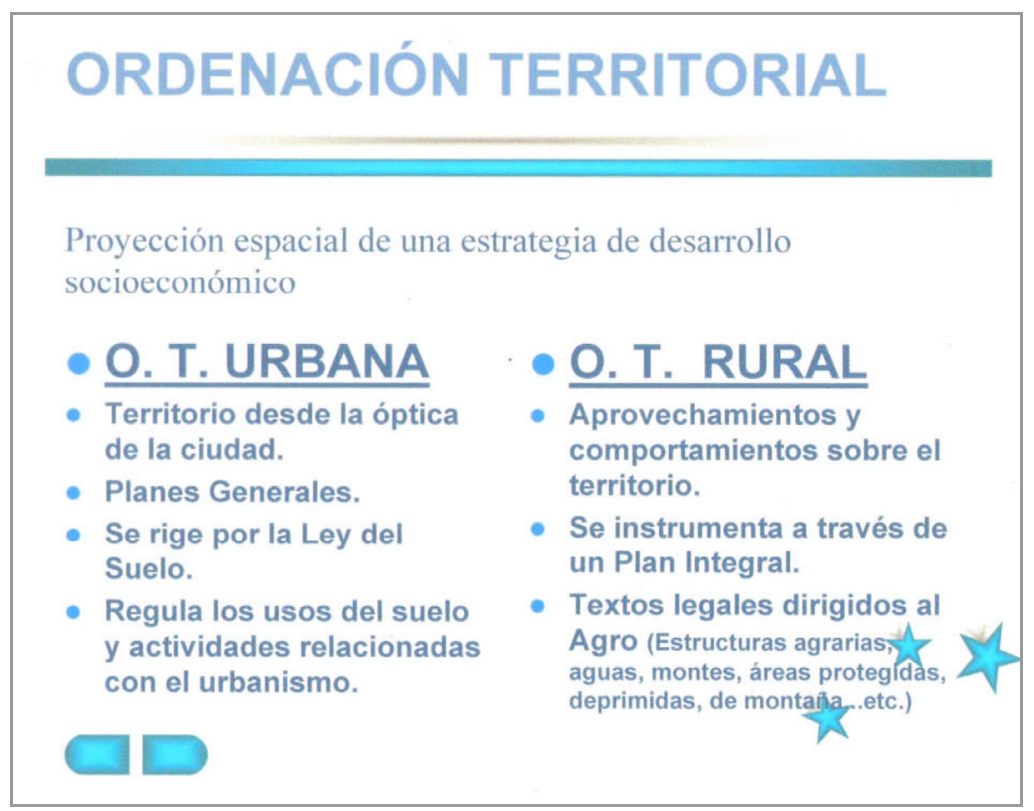


Figura 9: Definición de las zonas rurales

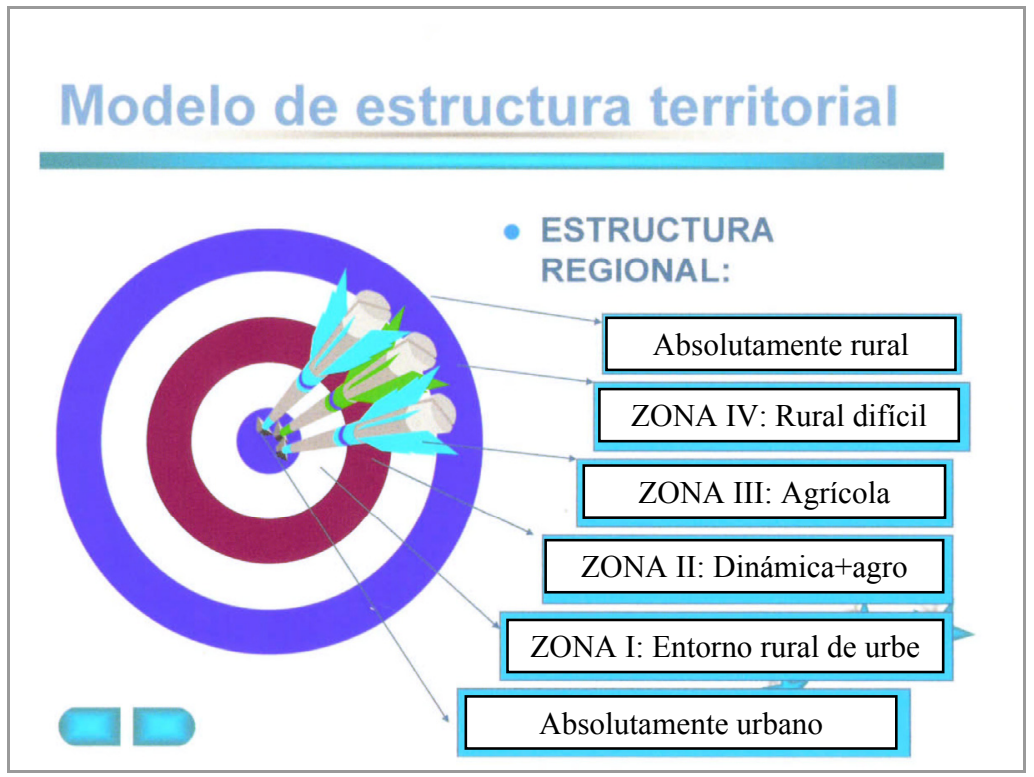

Figura 10: Defectos Zona I (Coef. Propuesto, 2,0)

\section{Principales problemas según las zonas}

\section{- Zona I:}

- Cambio de uso del suelo de rústico a urbano.

- Abandono del aprovechamiento agrario.

- Contaminación de origen urbano.

- Presión ( recreativa... Etc.) sobre los habitantes

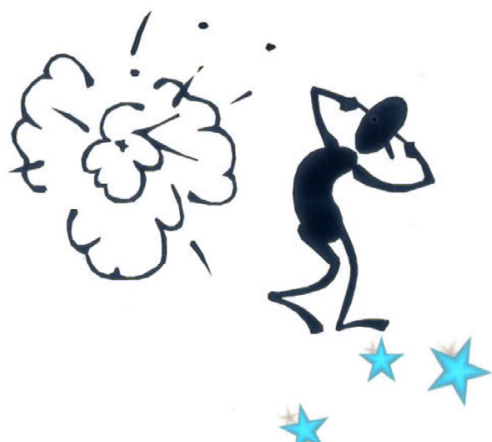


Figura 11: Defectos Zona II (Coef. Propuesto, 1,75)

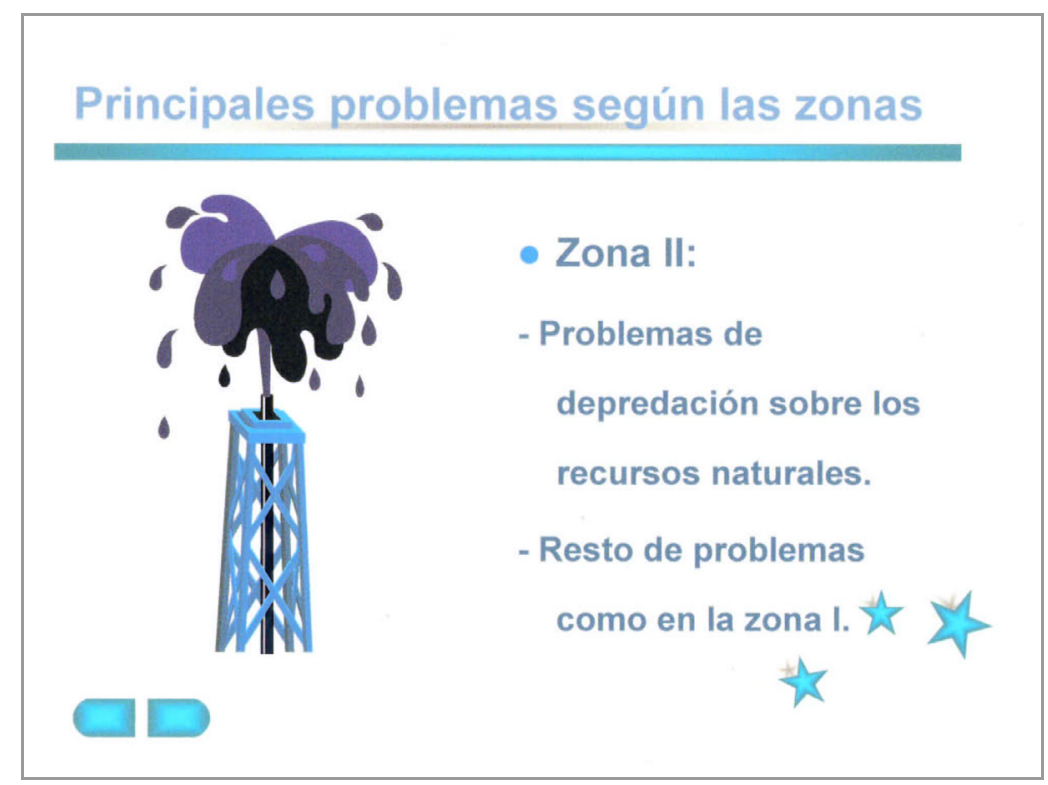

Figura 12: Características Zona III (Coef. Propuesto 1,5)

\section{Principales problemas según las zonas}

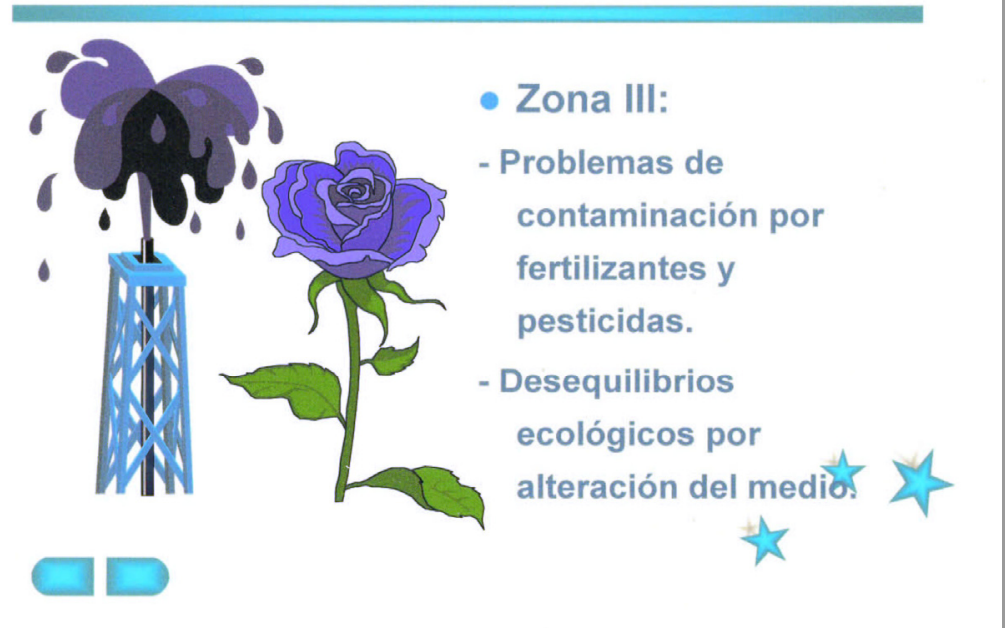


Figura 13: Defectos Zona IV (Coef. Propuesto, 1,0)

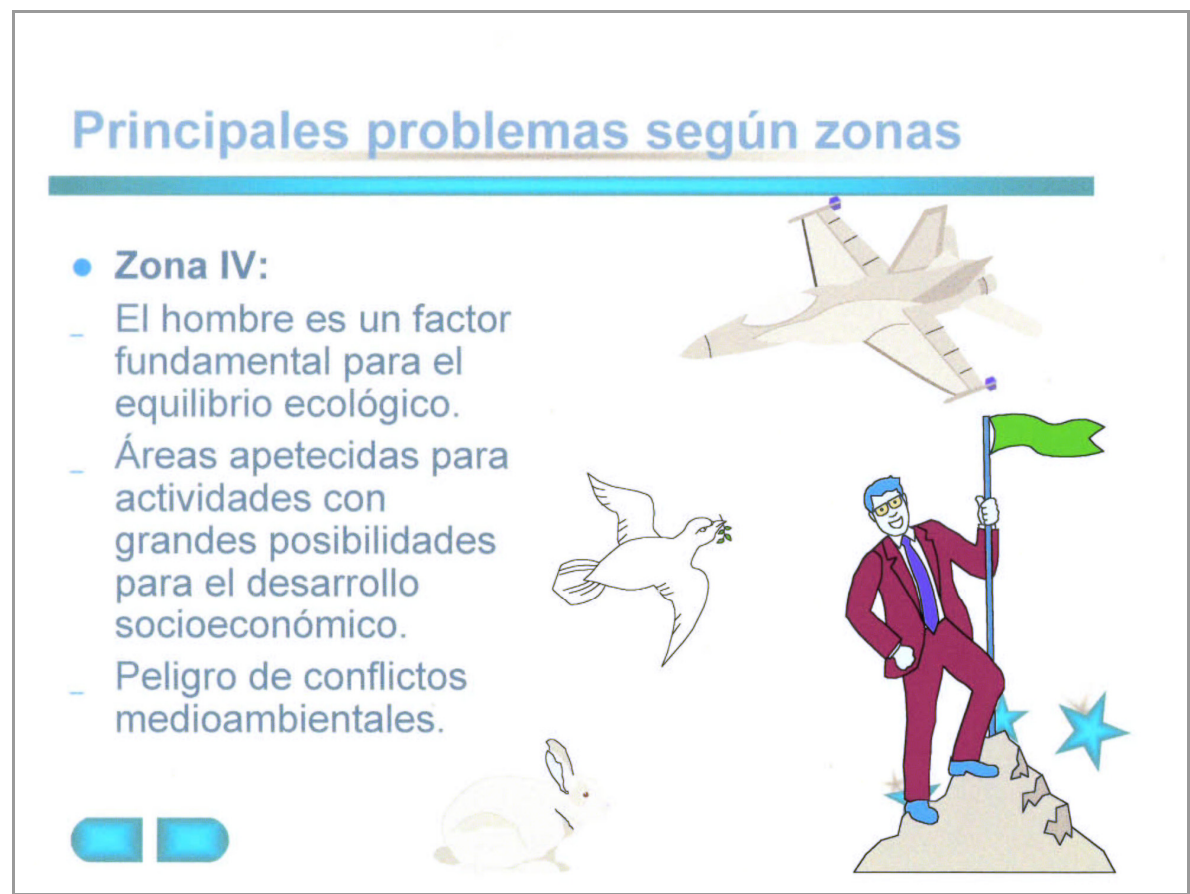

Por la proximidad del Área abarcada por este estudio a núcleos de población rural o a centros de actividad económica agraria (naves relacionadas fundamentalmente con la actividad agrícola), se considera que el factor de ponderación debe ser 1,5 (uno y medio) puesto que la zona de explotación agrícola típica, según el Modelo de Desarrollo Regional, es la Zona III.

en regadío

6.1. Capitalización por posición respecto a núcleo urbano

Con lo que, con la afección, ya incluida en el método de capitalización de rentas, del $5 \%$ que autoriza la propia ley de expropiación forzosa, se tiene: 

forzosa por las obras del AVE en la provincia de León

Tabla 15: Capitalización de rentas en "labor regadío" con Índice de territorialidad

\begin{tabular}{|l|c|c|c|c|c|c|}
\hline \multicolumn{1}{|c|}{$\begin{array}{c}\text { Hipótesis } \\
\text { de cálculo }\end{array}$} & $\begin{array}{c}\text { Renta } \\
\text { en } \mathbf{\epsilon} / \mathbf{h a}\end{array}$ & $\begin{array}{c}\text { Tasa de } \\
\text { capitalización }\end{array}$ & $\begin{array}{c}\text { Valor en } \\
\boldsymbol{\epsilon} / \mathbf{h a}\end{array}$ & $\begin{array}{c}\text { Valor con } \\
\text { afección del } \\
\mathbf{5 \%} \text { en } \boldsymbol{\epsilon} / \mathbf{h a}\end{array}$ & $\begin{array}{c}\text { Valor con } \\
\mathbf{1 , 5} \text { de índice } \\
\text { territorial } \\
\text { en } \mathbf{\epsilon} / \mathbf{h a}\end{array}$ & $\begin{array}{c}\text { Valor unitario } \\
\text { de la finca por } \\
\text { capitalización } \\
\text { rentas } \mathbf{\epsilon} / \mathbf{m}^{2}\end{array}$ \\
\hline $\begin{array}{l}\mathrm{R}=0,4(\mathrm{I}-\mathrm{G}) \\
\text { (Renta mínima) }\end{array}$ & $1.064,48$ & 4,00 & $26.612,00$ & $27.942,60$ & $41.913,90$ & 4,19 \\
\hline $\begin{array}{l}\mathrm{R}=\mathrm{I}-\mathrm{G}-\mathrm{B} \text { con } \\
\mathrm{B}=0,07 \times \mathrm{I} \\
\text { (Renta máxima) }\end{array}$ & $2.430,35$ & 4,00 & $60.758,75$ & $63.796,69$ & $95.695,04$ & 9,57 \\
\hline Media & $1.747,42$ & & & & & 6,88 \\
\hline
\end{tabular}

Con lo que el menor valor unitario de expropiación de las fincas de regadío es de $4,19 € / \mathrm{m}^{2}$.

\subsection{Capitalización por posición respecto a núcleo urbano}

en secano

Tabla 16: Capitalización de rentas con Índice de territorialidad en secano

\begin{tabular}{|l|c|c|c|c|c|c|}
\hline \multicolumn{1}{|c|}{$\begin{array}{c}\text { Hipótesis } \\
\text { de cálculo }\end{array}$} & $\begin{array}{c}\text { Renta } \\
\text { en } \boldsymbol{\epsilon} / \mathbf{h a}\end{array}$ & $\begin{array}{c}\text { Tasa de } \\
\text { capitalización }\end{array}$ & $\begin{array}{c}\text { Valor en } \\
\mathbf{\epsilon} / \mathbf{h a}\end{array}$ & $\begin{array}{c}\text { Valor con } \\
\text { afección del } \\
\mathbf{5 \%} \text { en } \boldsymbol{\epsilon} / \mathbf{h a}\end{array}$ & $\begin{array}{c}\text { Valor con } \\
\mathbf{1 , 5} \text { de índice } \\
\text { territorial } \\
\text { en } \boldsymbol{\epsilon} / \mathbf{h a}\end{array}$ & $\begin{array}{c}\text { Valor unitario } \\
\text { de la finca por } \\
\text { capitalización } \\
\text { de rentas } \mathbf{\epsilon} / \mathbf{m}^{2}\end{array}$ \\
\hline $\begin{array}{l}\mathrm{R}=0,5(\mathrm{I}-\mathrm{G}) \\
\text { (Renta mínima) }\end{array}$ & 575,90 & 4,00 & $14.397,50$ & $15.117,38$ & $22.676,07$ & 2,27 \\
\hline $\begin{array}{l}\mathrm{R}=\mathrm{I}-\mathrm{G}-\mathrm{B} \text { con } \\
\mathrm{B}=0,07 \times \mathrm{I} \\
\text { (Renta máxima) }\end{array}$ & $1.243,88$ & 4,00 & $31.097,00$ & $32.651,85$ & $48.977,78$ & 4,90 \\
\hline Media & 909,89 & & & & & 3,59 \\
\hline
\end{tabular}

Con lo que el menor valor unitario de expropiación de las fincas de secano es de $2,27 € / \mathrm{m}^{2}$.

\subsection{Capitalización por posición respecto a núcleo urbano}

en Árboles de ribera 
Tabla 17: Capitalización de rentas con Índice de territorialidad en Árboles de ribera

\begin{tabular}{|c|c|c|c|c|c|c|}
\hline $\begin{array}{l}\text { Hipótesis } \\
\text { de cálculo }\end{array}$ & $\begin{array}{c}\text { Renta } \\
\text { en } € / \text { ha }\end{array}$ & $\begin{array}{c}\text { Tasa de } \\
\text { capitalización }\end{array}$ & $\begin{array}{c}\text { Valor en } \\
\text { €/ha }\end{array}$ & $\begin{array}{c}\text { Valor con } \\
\text { afección del } \\
5 \% \text { en } € / h a\end{array}$ & \begin{tabular}{|c|} 
Valor con \\
1,5 de índice \\
territorial \\
en $€ /$ ha \\
\end{tabular} & $\begin{array}{l}\text { Valor unitario } \\
\text { de la finca por } \\
\text { capitalización } \\
\text { de rentas } € / \mathrm{m}^{2} \\
\end{array}$ \\
\hline $\begin{array}{l}\mathrm{R}=0,4(\mathrm{I}-\mathrm{G}) \\
(\text { Renta mínima) }\end{array}$ & 963,29 & 4,00 & $24.082,25$ & $25.286,36$ & $37.929,54$ & 3,79 \\
\hline $\begin{array}{l}\mathrm{R}=\mathrm{I}-\mathrm{G}-\mathrm{B} \text { con } \\
\mathrm{B}=0,07 \times \mathrm{I} \\
\text { (Renta máxima) }\end{array}$ & $2.195,15$ & 4,00 & $54.878,75$ & $57.622,69$ & $86.434,03$ & 8,64 \\
\hline Media & $1.579,22$ & & & & & 6,21 \\
\hline
\end{tabular}

Con lo que el menor valor unitario de expropiación de las fincas de árboles de ribera es de $3,79 € / \mathrm{m}^{2}$.

7. TASACIONES COMPLEMENTARIAS EN APLICACIÓN DEL "PRINCIPIO DE FINALIDAD"

7.1. Tasaciones complementarias para "Labor regadío" en aplicación del "Principio de finalidad"

regadío

7.1.1. Valor de la finca incluyendo su infraestructura de

El valor unitario de las infraestructuras de la zona regable se estima, como ya se ha comentado, en $0,3 € / \mathrm{m}^{2}$ para las zonas regables de Villanueva de las Manzanas y Santas Martas.

Los representantes de la Comunidad de Regantes, indican en el transcurso de la visita a la zona, que las obras para implantar el regadío supusieron un coste medio de alrededor de $3000 € /$ ha hace ocho años, como se puede comprobar en los documentos que poseen, por lo que se deberá sumar lo que corresponde como valor añadido a las fincas, según la superficie de las mismas.

\subsubsection{Valoración de las obras de reposición del regadío}

Suponiendo que el coste que figura en el apartado anterior, a los efectos de las nuevas obras en la parte de la parcela no expropiada, se mantenga en el momento de su ejecución, se estima un coste de 0,3 $€ / \mathrm{m}^{2}$ (Se hace coincidir con el presupuesto de implantación del regadío 
puesto que así se incluyen las obras accesorias necesarias como entradas, acequias, drenajes y cuantas obras sean necesarias).

\subsubsection{Valoración de las cosechas pendientes (C.P.)}

Se van a calcular teniendo en cuenta si se trata de cereales o de pastos, según las expresiones:

- Cultivos:

$$
\begin{aligned}
\text { C.P. } & =\mathrm{G}+0,08 \times \mathrm{I}= \\
& =635,80+0,08 \times 3.297,70= \\
& =899,60 € / \mathrm{ha}=0,08996 € / \mathrm{m}^{2} \approx 0,1 € / \mathrm{m}^{2}
\end{aligned}
$$

(Se observa que coincide con lo que propone la entidad expropiante).

- Pastos:

$$
\begin{aligned}
\text { C.P. } & =\mathrm{G} / 2+0,04 \times \mathrm{I}= \\
& =635,80 / 2+0,04 \times 3.297,70= \\
& =449,80 € / \mathrm{ha}=0,04498 € / \mathrm{m}^{2} \approx 0,05 € / \mathrm{m}^{2}
\end{aligned}
$$

(Se observa que coincide con lo ofrecido por la entidad expropiante).

Es importante hacer notar esta coincidencia entre la valoración de la entidad expropiante y la valoración propuesta en este trabajo, en lo que se refiere a cosechas pendientes, puesto que esto significa que la propuesta de ingresos y gastos de la que se ha partido en ambos casos es similar y, dado que este apartado suele ser la base del cálculo posterior, no es fácilmente explicable, aplicando la normativa vigente en esta materia, la divergencia tan acusada que existe entre los resultados de este trabajo y los de la entidad expropiante.

7.1.4. Valoración de la ocupación temporal en los regadíos

La entidad expropiante informa que la ocupación temporal será de dos años y se va a calcular según la expresión:

$$
\text { O.T. }=(0,08 \times \mathrm{I}+\mathrm{G}=0,08 \times 3.297,70+635,80) \times 2=1.799,23 € / \mathrm{ha}
$$

7.1.5. Valoración de los costes del proceso

Se estiman en un $10 \%$ de la indemnización correspondiente. 
7. 2. Tasaciones complementarias para "Labor secano" en aplicación del "Principio de finalidad"

7.2.1. Valoración de las cosechas pendientes (C.P.) en los secanos

Se van a calcular según la expresión:

C.P. $=\mathrm{G}+0,08 \times \mathrm{I}=163,60+0,08 \times 1.315,40=268,83 € / \mathrm{ha}$

\subsubsection{Valoración de los costes del proceso}

Se estiman en un $10 \%$ de la indemnización correspondiente.

\section{CONCLUSIONES}

La ley del suelo 8/2007 introduce el concepto de "Valor Expropiatorio" de una finca rústica diferente del valor de tasación del mismo bien para cualquier otro fin permitiendo que el coste para el propietario de bien, intente ser similar al asumido por el resto de la sociedad y no, como ocurre hasta ahora, el coste sea mayor en su caso.

No se contempla indemnización por expropiación parcial, en los casos en los que no hay división de lo no expropiado, cuando la reducción de superficie y las distorsiones geométricas en la forma y accesos a las parcelas lo hacen necesario.

El demérito propuesto por la entidad expropiante es excesivamente bajo y sólo permitido para los "restos" no expropiados que se subdividen incrementando los problemas de acceso a las fincas y aumentando las dificultades de explotación de los mismos.

El valor asignado a las fincas por la entidad expropiante es de aproximadamente la tercera parte del valor mínimo unitario con que se debiera indemnizar a los propietarios, lo cual resulta un fuerte retroceso en las expectativas de desarrollo rural de la zona.

Por todo ello, es deseable que, desde las instituciones competentes en esta materia, se tomen medidas para disminuir los perjuicios de una expropiación forzosa realmente dura para las fincas expropiadas. La sostenibilidad es un principio que exige que se pague lo que es justo para los perjudicados en aras del interés social que, indudablemente, tiene la construcción de este tipo de infraestructuras. 

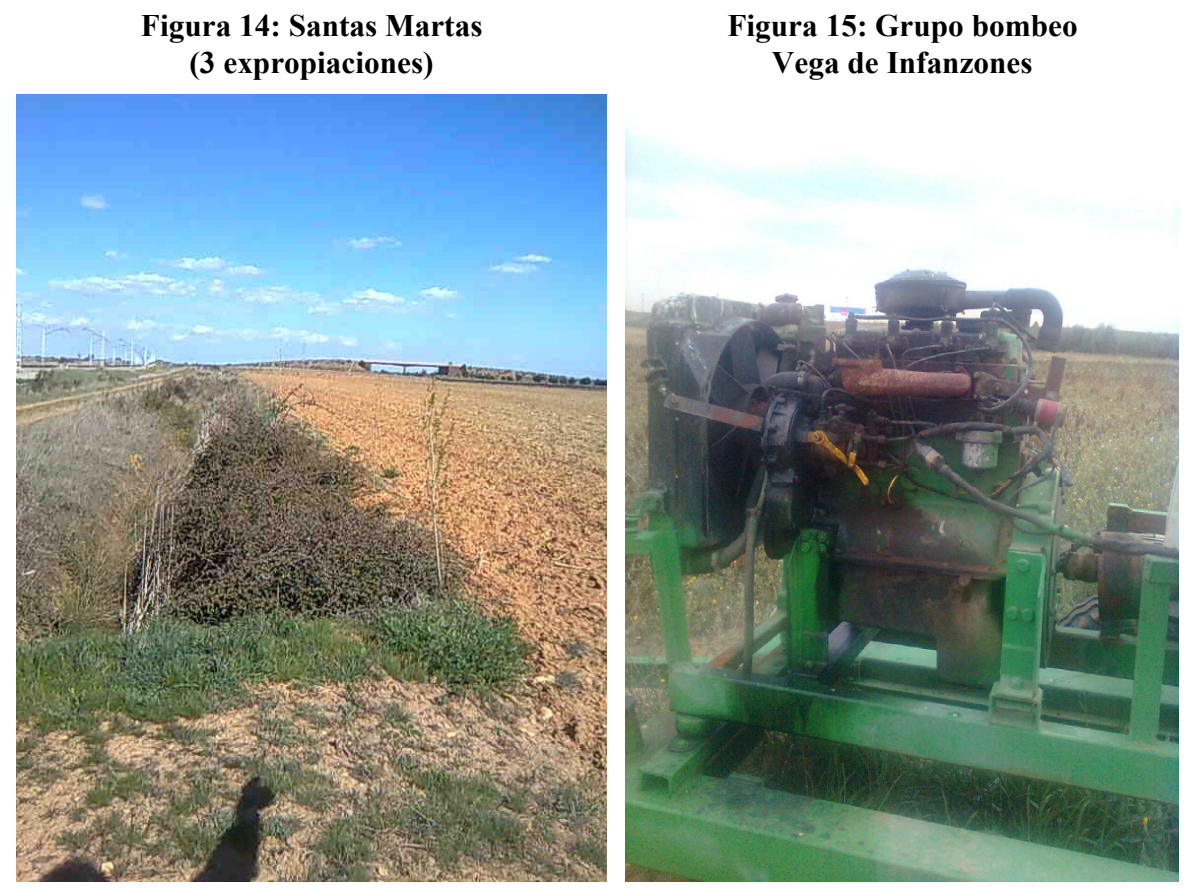

\section{BIBLIOGRAFÍA}

Alonso Sebastian, R. y A. Serrano Bermejo (1991) Los costes en los procesos de producción agraria. Madrid: Mundi-Prensa.

Alonso Sebastian, R. y M.T. IRURETAGOYENA (1994) Valoración agraria. Concepto, métodos y aplicaciones. Madrid: Mundi-Prensa.

CABALleR, V. (1993) Concepto y métodos de valoración agraria. Madrid: Mundi-Prensa.

CABAlleR, V. (2008) Valoración agraria. Teoría y práctica. Madrid: Ed. Mundi-Prensa.

GARCíA GómEZ DE MERCADO, F. (2001) Legislación de expropiación forzosa Comentarios y jurisprudencia, $2^{\mathrm{a}}$ edición. Madrid: Comares.

Gómez OREA, D. (2007) Ordenación territorial. Madrid: Ed. Mundi-Prensa.

Guadalajara, N. (1996) Valoración Agraria. Casos Prácticos, $2^{a}$ edición. Madrid: Ed. Mundi-Prensa. 
MORENO GIL, O. (2000) Expropiación Forzosa. Legislación y jurisprudencia comentadas, $2^{a}$ edición. Madrid: Civitas.

Olmeda, M.; L.M. Rivera, B. Segura y J.L. Martínez (1989) Métodos de valoración agraria. Colegio Oficial de Ingenieros Agrónomos de Murcia.

PÉREZ-SALAS SAgReraS, J.L. (2005) "La valoración parcial de bienes por utilidad pública", Agrónomos, 31, julio, pp. 5-16.

RUIZ GARCíA, F. (1986) Manual de valoración agraria y urbana. Madrid: Ed. Intervalora.

Vidal, F.; M. Brugarolas, J.F. del Campo, M. Fernández, M.A. Martín, A. MELIÁN y J.M. SALES (2002) Economía Agraria y Valoración. Elche: Ed. Miguel Hernández.

Vidal, F.; L. Martínez-CARRasco, M.A. Martín y J.M. Sales (2000) Aplicaciones Prácticas de la Valoración Agraria. Elche: Ed. Limencop. 